


\title{
La otra Nueva España de Andrés Henestrosa: reflexiones de un amigo de los republicanos
}

\author{
Andrés Henestrosa's La otra Nueva \\ España: reflections from a friend of the \\ republicans
}

Manuel López Forjas1

Universidad Autónoma de Madrid

\begin{abstract}
Resumen
En este trabajo se pretende rescatar las memorias y reflexiones sobre la España republicana del escritor oaxaqueño Andrés Henestrosa, quien llegó a sumar 102 años de vida hasta el año de 2008, cuando falleció. Para ofrecer un panorama que sirva también de introducción a su obra ensayística, se presenta en primer lugar un comentario general sobre el debate que se presentó en México en los años posrevolucionarios sobre las posturas hispanistas en el mundo intelectual y literario; tratando de situar a Henestrosa dentro de ese contexto. En la segunda parte de esta exposición, se verá cómo el escritor oaxaqueño -reivindicando la raíz mestiza como la más influyente en la configuración del México contem-
\end{abstract}

1 Este trabajo se enmarca dentro del proyecto de investigación predoctoral de Formación del Personal Investigador (FPI) financiado por la Universidad Autónoma de Madrid, convocatoria 2015, en el Instituto Universitario La Corte en Europa (IULCE). Para comunicarse con el autor del texto, se puede escribir a manuel.lopezf@uam.es 
poráneo- ofreció una explicación distinta donde intentó rescatar las raíces históricas del pueblo mexicano, poniéndolas en relación con el aporte de los españoles republicanos que conoció.

Palabras clave: Henestrosa, indigenismo, hispanismo, mestizaje, republicanos españoles.

\begin{abstract}
This article attempts to rescue the memories and reflections about the Spanish Republic written by the Oaxacan author Andrés Henestrosa, who lived for 102 years (he died in 2008). To offer a complete view that also helps as an introduction to his essays, in first place there will be a general comment about the ideological discussion that happened in México after the Mexican Revolution around the Hispanic attitudes in the intellectual and the literary world, trying at the same time to situate to Henestrosa in this context. In the second part of this exposition, it will be possible to perceive how the Oaxacan writer -vindicating the "mestizo" root as the most influential in the current México's political configuration- presented a different explanation where he strove to rescue the historical roots of the Mexican people, relating them with the contributions of the Spanish Republicans that he met in his life.
\end{abstract}

Keywords: Henestrosa, Indigenism, Hispanism, Miscegenation, Spanish Republicans.

\title{
1. Nota biográfica
}

ndrés Henestrosa nació en San Francisco Ixhuatán, en el esta-
por su madre, Martina Henestrosa, de quien asumiría el apellido
tras no conocer a su padre Arnulfo Morales, emigró a la ciudad de
México a los 16 años para buscar mejores condiciones de vida; des-
pués de una infancia hablada en zapoteca, viviendo entre el monte 
y el pueblo de Ixhuatán. Después de sobrevivir prácticamente en la mendicidad, con un mínimo conocimiento de la lengua española, logró ver a José Vasconcelos en su oficina-quien presidía la recién creada Secretaría de Educación Pública-y, tras su insistencia, consiguió una pensión para estudiar en la Escuela Nacional de Maestros. El autor de La raza cósmica le obsequió la colección de libros "verdes", cuya edición tenía el fin de difundir la cultura universal en México. El joven Andrés solía pasear con frecuencia por las calles de la capital, ausentándose de algunas clases, pero jamás de las lecturas (a pesar de no entenderlas en su mayoría).

Tuvo que abandonar definitivamente la Escuela Normal de Maestros, porque la trasladaron al barrio de San Jacinto y no podía llegar caminando hasta allí. Después de varias penurias, conoció a la mecenas más importante de México en ese momento: Doña Antonieta Rivas Mercado (Reyes, 2005: 80-93). Ella fue una de las personas más importantes en su vida, no sólo por ofrecerle alojamiento y encargarse de sus gastos; sino también porque lo involucró en las tertulias donde participaban los grandes exponentes del mundo literario de ese momento. Andrés se graduó de Bachiller en la Escuela Nacional Preparatoria (ubicada en el Antiguo Colegio de San Ildefonso) y comenzó a estudiar Leyes en la Escuela Nacional de Jurisprudencia, donde recibió clases de Antonio Caso. Fue durante las clases del filósofo donde surgió su libro Los hombres que dispersó la danza, una colección de leyendas zapotecas.2

Por la relación cercana que tenía Antonieta con Vasconcelos, Andrés se unió a la campaña para la contienda presidencial de

2 La primera edición fue promovida por Antonieta Rivas Mercado. Hay otra edición que hizo el Fondo de Cultura Económica en 1992 y la más reciente fue hecha por Miguel Ángel Porrúa, 2009. Esta obra constituye ya una expresión temprana donde integró las tradiciones autóctonas con los medios literarios de Occidente, a través de los primeros poetas épicos -constituyentes de la forma originaria común a los romances castellanos y las leyendas de los pueblos indígenas- (Martínez, 1942: 14, 21). 
1929, encabezada por el propio ex-rector de la UNAM. Recorrió todo el país con él y otros jóvenes vasconcelistas, como el escritor Mauricio Magdaleno y el que fuera presidente de México (19581964), Adolfo López Mateos. Sin embargo, Pascual Ortiz Rubio fue declarado ganador electoral; lo que la oposición -los vasconcelistas, que incluso fueron perseguidos y atacados con violenciadenunció como el mayor fraude en la historia nacional. José Vasconcelos abdicó de sus aspiraciones políticas tras ese revés y se fue a Estados Unidos y luego a París. En la "Ciudad Luz" doña Antonieta Rivas Mercado terminaría con su vida dentro de la Catedral de Nôtre Dame, ocasionándole a José y a Andrés un enorme pesar. Andrés se quedó en México, escribiendo artículos periodísticos, la mayoría por invitación del escritor Fernando Benítez y llegó a vivir con el fotógrafo francés Henri Cartier-Bresson y el escritor estadounidense Langston Hughes (Reyes, 2005: 133).

Durante el gobierno de Lázaro Cárdenas, Henestrosa fue nombrado Historiador de la Secretaría de Relaciones Exteriores y después de no recibir la beca de la Fundación Guggenheim en la primera convocatoria, sí lo logró en la segunda ronda. El 18 de julio de 1936, coincidiendo con el inicio de la Guerra Civil Española, se fue becado a Estados Unidos con un espíritu cabizbajo y considerándose también como un exiliado -tras el fraude electoral que había roto el proyecto de nación vasconcelista- (Reyes, 2005: 136). Sin querer residir en un solo lugar, pasó por la Universidad de Berkeley, la Universidad de Illinois, la Universidad de Tulane hasta llegar a Nueva York, donde se reencontró con Langston Hugues $y$, junto con él, compartió alojamiento con el tabasqueño Andrés Iduarte y el cubano Julio Girona (Reyes, 2005: 152). Pudo renovar su beca un año más y, aunque Ruth Dworkin -pianista de Chicago y gran amiga suya- le pedía que se quedara con ella para seguir compartiendo sus gustos por el arte, él decidió regresar a México. De la carta que le escribió, surgió el Retrato de mi madre, obra 
elogiada por Octavio Paz, quien la publicaría en su revista Taller.3 En ese breve pero revelador texto, Andrés relató sus recuerdos de niñez y cómo se alivió cuando su madre al fin le contó la historia de su padre:

No duró mucho aquel amor. Doce años después de casados mi padre murió. Mucho tiempo para el sufrimiento, pero un instante para la dicha. Dos semanas después de su entierro volvimos a Ixhuatán a donde no pudo llegar a morir porque una sublevación de juchitecos lo impidió (Henestrosa, 1967a: 5)

Martina Henestrosa, Tina Man, era una madre al estilo juchiteca; es decir, vivía en una sociedad donde la mujer tenía un papel preponderante en la educación de la familia y su administración. Andrés, conjuntando ese profundo cariño hacia su madre con las tradiciones más famosas de la zona del Istmo de Tehuantepec compuso los versos de una canción que hasta el día de hoy se conoce como La Martiniana. Henestrosa estaba recreando ese momento que había relatado en Retrato de mi madre -donde su madre le reveló la verdad sobre la vida de su padre frente a los rumores que Andrés había escuchado-. De repente, se levantó por la noche y comenzó a escribir unos versos, imaginándose el sonido de unos

3 "[...] esas páginas no tienen una sola arruga: poseen la juventud sin edad de las obras que se acercan a la perfección. Un lenguaje nítido, nunca excesivo, a un tiempo reservado y tierno, sobrio y luminoso. Una prosa de andadura ligera, que nunca se precipita y nunca se retrasa: una prosa que llega a tiempo siempre. La historia, simple y contada con palabras transparentes, provoca en el lector una emoción en la que se alía lo más antiguo a lo más fresco, como oír un cuento de otra edad del mundo. Pocas veces la prosa moderna de nuestra lengua ha logrado tal fluidez de agua corriente. Agua para beber y agua para contemplar su fondo ondeante, no nuestros rostros interrogantes sino un paisaje que se entrelaza y desenlaza en vibraciones y centelleos: mujeres, hombres, niños, burros, bueyes, vacas, nubes, un árbol llameante en un llano quemado. El tiempo y sus apariciones: agua de la memoria” (Paz, 2001: 353-354). 
instrumentos de viento y cuerda de fondo, con un ligero silbido. Ese poema lo adaptaría a la música de un famoso son istmeño para terminar su proeza, después de componer la letra en 1957:

Niña, cuando yo muera / no llores sobre mi tumba/ cántame un lindo son, ay mamá/ cántame la sandunga/ Tarareaba una música inventada tocada por bandas de aliento e instrumentos de cuerda: "No me llores, no/ porque si lloras me muero/ en cambio si tú me cantas/ yo siempre vivo y nunca muero/Lucero de la mańana/ la flor de todos los sones/ canta La Martiniana, ay mamá/ y alegra los corazones (Reyes, 2005: 253-254)

\section{Amigo de los republicanos en la otra Nueva España}

A su vuelta a México, el periodista Antonio Vargas MacDonald le pidió que escribiera artículos sobre la Guerra Civil Española y la actitud favorable de Cárdenas hacia los exiliados. En ese ejercicio, Andrés jugó un papel de mediador en la sociedad mexicana, porque a nivel político e ideológico era un tema bastante polémico. Por su parte, él se consideraba un republicano y apoyaba la apertura diplomática del presidente; además de que en su interior sentía que no sólo actuaba de un modo altruista, pues veía que los exiliados españoles eran personas cultas que propiciarían un mayor desarrollo en el país. Sin embargo, debía tener cuidado para matizar todas las declaraciones, en un intento de convencer a los mexicanos que se oponían a la llegada de los españoles: en general eran católicos conservadores o intelectuales (como Alfonso Junco) o personas que se habían visto afectadas por las reformas sociales. La idea era presentar a los republicanos como hermanos que llegaban a colaborar, que no tenían intenciones de quitar las tierras de los campesinos ni formar grupos de extrema izquierda que radicalizaran a la sociedad (Reyes, 2005: 158). 
Andrés fue a recibir a Veracruz a los más de 1500 pasajeros del Sinaia, en compañía de Pancho Trejo, quien los acogería con mucha hospitalidad. Así comenzó una amistad con Emilio Prados, Juan Rejano y Luis Araquistáin; quienes comenzaron a colaborar con él en el periódico El Nacional y a participar en las tertulias del Café París, donde Octavio Paz lo había visto para pedirle su contribución para Taller (Reyes, 2005: 159). Andrés se casó con una juchiteca, oaxaqueña como él, de nombre Alfa Ríos el 24 de mayo de 1940, usando un traje que le prestó José Bergamín. De ese matrimonio nació Cibeles Henestrosa, única hija de Alfa y Andrés. Por cuestiones del trabajo, vivieron en la ciudad de México y, tras conseguir más grupos en la Escuela Normal, se mudaron a la colonia Tabacalera donde vivían la mayoría de los exiliados españoles como Emilio Prados, Florentino M. Torner, Juan Rejano, Antonio Rodríguez Luna, José Herrera Petere, Pedro Garfias, Lorenzo Varela y Ferrand de Pol; por lo que a Henestrosa le gustaba llamarla "colonia Nueva España" (Reyes, 2005: 172, 218).4 Durante estos años, la cultura en la capital mexicana se enriqueció de modo importante, precisamente por la apertura de los mismos españoles a participar en los eventos, reuniones y tertulias que los mexicanos organizaban con mucha frecuencia. Juan Rejano y León Felipe, por ejemplo, se integraron a los "Viernes poéticos" en el Palacio de Bellas Artes (Reyes, 2005: 234).

\section{Charlas mexicanas: debates sobre la herencia española}

El carácter "antiyanqui" del liberalismo mexicano e iberoamericano (o hispanoamericano) es un elemento imprescindible para

4 En una entrevista con Guadalupe Loaeza, Henestrosa narra que la primera vez que se llamó Nueva España fue por Hernán Cortés, cuando llegó a Veracruz y quedó maravillado con lo que había visto. Según él, eso lo retomó Bernal Díaz del Castillo posteriormente. 
catalogar a los autores en la lucha antiimperialista. Es más que sabido que esa impronta constituye casi una obligación para la tradición liberal mexicana, porque implica no un sentido xenófobo, sino hondamente político, histórico, económico y social. Aunque Andrés Henestrosa debía parte de su formación a las universidades estadunidenses, es preciso señalar que allí se dedicó a meditar sobre los problemas de España y la América de habla española. Como ensayista, conocía perfectamente el contexto en que se movía; pero trataba de defender su causa unida al proyecto martiano de Nuestra América que veía reflejado en la causa de Fidel Castro y la Revolución Cubana. Es interesante saber que Henestrosa gestionó la liberación de Castro y lo llegó a conocer en México, donde hablaron sobre la necesidad de derribar el gobierno de Batista (Reyes, 2005: 243-245).5

Por esta razón, hacia 1955 comenzó a publicar en el periódico Novedades y, en su primer artículo titulado Libro falaz, criticó con mucho cuidado y defensa patria a un libro de Graham Green que hablaba mal de los ojos negros de las mexicanas, de la baja estatura de los hombres, de los monumentos erigidos a hombres muertos por violencia y, en suma, que definía a México como un país atrasado. Andrés, no obstante de responder puntualmente a las críticas, se tranquilizó y agregó que ese libro podría ser útil para exaltar el sentido de la mexicanidad entre quienes lo sentían. Alfonso Reyes lo llamó felicitándolo al otro día de que saliera publicado su artículo (Reyes, 2005: 230).

Con esta síntesis, se puede perfilar la relación de los intelectuales mexicanos con Estados Unidos. Sin embargo, no queda tan clara la relación con el problema de España. Más allá de las clasificaciones de "hispanofilia" o "hispanofobia" que arrastran concepciones esencialistas de la realidad sin confrontarse con las cuestiones so-

5 Henestrosa fue amigo de Raúl Roa García y conoció su obra José Martí y el destino americano (1938). 
ciales, políticas e históricas de un modo más riguroso; es necesario tener en consideración las consecuencias ideológicas (base de la política social) que se desprendían al emitir un juicio "hispanista" en el México de mitad del siglo XX. Si se recuperaba el pasado "colonial", ya fuere en términos de "la grandeza del Virreinato" o la amplia cultura expresada en Sor Juana y en las catedrales; se solía hacer en detraimiento de las culturas indígenas -tanto antiguas como contemporáneas-. Esa actitud solía perseguir un fin apologeta del credo católico, en su vertiente más espuria (la imperial), la cual se reflejó claramente en la resistencia de varios sectores de mexicanos católicos que se opusieron con fervor a la llegada de los exiliados republicanos; por no hablar de los círculos abiertamente franquistas en México (Sola, 2014: 180).

Henestrosa fue nombrado candidato para ser diputado por Oaxaca para la XLIV Legislatura (1958-1961), en la cual formaría parte de las Comisiones Permanentes y Especiales de Asuntos Indígenas, Editorial y Turismo. Antes de iniciar su campańa, Eulalio Ferrer, exiliado español que había fundado la compañía de publicidad Anuncios Modernos y que trabajaba para Telesistema Mexicano, lo llamó junto con Vasconcelos y Alfonso Junco -uno de los que más hostilidad mostró ante los republicanos- para hacer un programa de televisión. Quería que hablaran sobre temas de México y su historia, y que la audiencia se comunicara con cartas, telegramas o llamadas telefónicas. Andrés destacaba por mantener una posición contraria a los dos colegas, quienes negaban el México posrevolucionario. Los tres aceptaron ir al programa, llamado Charlas Mexicanas, con una duración de 15 minutos cada uno y que sería transmitido los jueves por la señal de XHGC-Canal 5. No obstante el perfil esperado de José Vasconcelos en la primera transmisión reivindicó la importancia de Ricardo Flores Magón en la configuración del México contemporáneo (Reyes, 2005: 259-261). Junco, aceptando su tesis, comentó sobre el rol del diario Regeneración y 
Andrés se refirió a El Hijo del Ahuizote por la condena de las prácticas de opresión hacia el pueblo:

Cuando se creía solo y hablaba para sí, en lágrimas y no por falta de tinta, mojaba la pluma, que tenía de oro y acero. Y, como curándose de haber cedido a efusiones a primera vista ajenas a su naturaleza, escribió en algún lugar: 'Ser firme es cosa bien distinta a ser insensible'. He aquí un escritor y periodista que muy bien puede ponerse de ejemplo en los días que corren: uno que murió de su pluma y no medró con ella (Reyes, 2005: 262).

Vasconcelos era el que presidía y abría las mesas de diálogo, proponiendo una reflexión general para incitar el coloquio. Su postura reflejaba la ambigüedad descrita anteriormente: mientras que defendía la soberanía nacional frente a la hegemonía de los Estados Unidos, se llegó a declarar a favor de un imperialismo de raíces supuestamente hispánicas para favorecer la unidad, la integración y el progreso de la sociedad mexicana. Esta actitud no hacía justicia a las comunidades indígenas, a las cuales había querido "evangelizar en la cultura universal" en su etapa de Secretario de Educación Pública. No obstante, solía respetar las intervenciones de Andrés y sólo matizaba algún detalle desde su opinión. Por su parte, Alfonso Junco negaba toda aportación al México contemporáneo de la herencia indígena y exaltaba los valores de la monarquía católica y su labor en la conquista. Como puede inferirse, el mayor debate se gestaba entre él y Henestrosa, pero de una forma pausada, que respetaba el tiempo de intervención de cada uno y no solía haber interrupciones entre los pugilistas; salvo los comerciales del vino Evaristo I promocionado por la Casa Madero. Estas anécdotas son posibles de narrar gracias a la reconstrucción y actualización que hicieron la Filmoteca de la UNAM y TV UNAM, las cuales lograron rescatar cinco programas completos con una duración total de 130 minutos. Andrés sólo apareció en el primer programa, mien- 
tras que en los otros cuatro envió al médico y politólogo veracruzano Jorge Carrión en su lugar.6 Empero, se tiene noticia que en otro programa discutieron sobre "la intelectualidad mexicana vista a la luz de la influencia de los transterrados” (Reyes, 2005: 274).

\section{Sobre la identidad mestiza del pueblo mexicano}

Parece que Henestrosa logró conciliar esas dos vertientes, yendo más allá de la teoría: aplicándolo con el ejemplo en su vida. En primer lugar, desde su estancia en Estados Unidos se comprometió con la causa republicana, en miras de la lucha social de los obreros y campesinos españoles. Mientras estudiaba la traducción del zapoteco y del huave al español, se reunía con sus amigos españoles que estaban en la Universidad de Berkeley y enfatizaba discursos que recuperaban los ideales de España con un amplio espectro ideológico: desde el socialismo y anarquismo utópicos hasta los valores cristianos más altruistas. De esta forma, sentía que iba arraigando su raíz espańola, pero en unidad y reconciliación de indios y espańoles: como dos culturas y dos lenguas igualmente ilustres -a veces, incluso, con una ventaja de las civilizaciones prehispánicas sobre la europea-.

Es así como fue forjando la tesis de que no se puede concebir España sin América y América sin Espańa. Un americano, que se siente orgulloso de serlo, también lo debe hacer de su herencia espańola siempre y cuando (si y sólo si) un español reconozca que su cultura sólo se puede explicar gracias a las grandes influencias americanas, al menos desde 1492. Esto no lo explicó por la comparación de sistemas políticos, o el estado de desarrollo de la "ci-

6 Charlas Mexicanas, Documental, México, La Casa Universitaria del Libro, TV UNAM, 4 de octubre de 2004. Los programas comenzaron en 1957 y no se pudo definir con exactitud en esta investigación el número de programas totales que se grabaron. 
vilización" a la francesa, sino fijándose en las manifestaciones artísticas populares como la danza y la música. Cuando en su viaje de bodas de plata en Madrid oyó un fandango de Huelva cuya letra le remitió a la canción popular mexicana "La Llorona", no pudo decir más que: "La canción del Istmo de Tehuantepec es el llanto español en pupilas nativas" (Reyes, 2005: 138). De la misma forma, asumía su personalidad como indígena. En una carta a Griselda Álvarez, le decía:

¿No es cierto, Griselda, que vengo de muy lejos, de muy abajo, y que en mi corazón confluyen muchas sangres? ¿№ es verdad, Griselda, que este embrollo que suelo ser, es el resultado de tanta historia que en mí se junta? ¡Y luego quieren que yo sepa orientarme ante tantos caminos que se abren ante mis ojos, que yo atine la puerta, que yo dé con la palabra que busco! Yo no he podido hacer otra cosa, Griselda, que reconciliar en mi pecho a mis abuelos, que pacificar mi sangre. Creo que con eso basta, Griselda (Henestrosa, 1967b: s.n.)

Cuando sus amigos le pedían, casi exigiéndole, un mayor compromiso con la situación de los indios y que aprovechara su posición como diputado para satisfacer las necesidades de su pueblo, él respondía a Griselda Álvarez, escritora mexicana, que ante todo era un hombre de letras, no un político. Esto no significaba para él que desatendiera a las comunidades indígenas ni a los sectores marginados de la sociedad mexicana; sino que mediante su labor como escritor hacía su propia lucha y reivindicación de los indios. Tenía miedo de que sus colaboraciones a través de ese medio, que era su pasión, fueran censuradas y que su persona fuera encarcelada por participar activamente en algún movimiento social. Pensaba que:

El problema del indio no es de filantropía, de beneficencia; no es un problema de leyes, ni siquiera educativo; su problema es económico, el que una vez resuelto, todo les vendrá por añadi- 
dura. Indio no es raza, no es sangre, sino un estado de ánimo, una manera económica. En ser indio mi vanidad se funda, dijo el mestizo Ignacio Ramírez, lo digo yo. No he cerrado los ojos a la dolorosa realidad indígena, que seguirá siendo hasta en tanto toda la acción de los mexicanos no se consagre a liquidar una injusticia de siglos. Pero démosle salario fijo, trabajo constante y regular, démosle caminos y él solo, como apuntó Benito Juárez, sin que la ley lo obligue, mandará sus hijos a la escuela (Reyes, 2005: 279).7

Como se aprecia, él iba construyendo un ideal moral propio, esperando que sus compatriotas se contagiaran de él. Aunque por momentos parece que convierte en una esencia la idea de "ser indio" como un elemento de identidad mexicana, o incluso mencionar la idea de un "alma india" que ha persistido desde la Conquista (Charolet, 2004: 14);8 Henestrosa intentaba reflexionar sobre la historia de México en un sentido más bien armónico y de reconocimiento de los valores de libertad e independencia. La identidad indígena del mexicano, de existir, no correspondería a una cuestión de raza, sangre o color de piel; tal cual él pensaba su propio proyecto. Al proclamarse a sí mismo indio, no aludía tanto a las dos lenguas que hablaba antes que el español, sino que estaba reivindicando aquel sector social negado por las élites mexicanas:

pese a tanto grito en contrario, ser indio era y es, una manera de ser inferior... Pleitos he tenido con algunos que me reprochan que siendo blanco, según ellos, me proclame indio. Verdaderas batallas he librado con los que me reprochan llevar apellido tan español,

7 Lo que cita del Nigromante es un terceto que formuló como respuesta al apelativo de "indio" que le asignaron en un periódico de la ciudad de México dirigido por españoles, llamado "El Huracán": "En indio ser mi vanidad se fun$\mathrm{da}, /$ porque el indio socorre en su miseria/ a los vasallos de Isabel segunda" (Riva Palacio, 2006: 102).

8 Blanca Charolet cita a su vez Palabras de Andrés Henestrosa al recibir la medalla al Mérito Cívico "Eduardo Neri. Legisladores de 1913” en el año 2003. 
siendo el indio que soy que me digo... ¿ Usted indio? No lo diga, porque no es cierto, y porque nadie se lo va a creer, y sin decirlo, los pobres que así piensan entienden que me reduzco, porque ser indio a su entender es una manera de proclamarse gente menor, apenas si con crisma (Cruz Bencomo, 2003: 118).9

Por ello, se entiende que recibiera con alegría el nombramiento que lo incluía como miembro de la Academia Mexicana de la Lengua el 23 de octubre de 1964, más por comprometerse con su pueblo que por el mérito en sí. La literatura era para él un medio de compromiso con los más débiles y con los pobres (González Freire, 2015: 192). Ese espíritu lo incluyó en su discurso de ingreso a la Academia titulado Los hispanismos en el idioma zapoteco, donde reconoció su infantil vocación hispánica, pero admitiendo que el zapoteco era su lengua materna. José Rojas Garcidueñas, en la contestación a su discurso, insistió en que el español también era su lengua (Henestrosa, 1964: 142). Además, dicho texto sería el antecedente de un proyecto para redactar un "vocabulario zapoteco-espańol/espańol-zapoteco que no se había hecho desde tiempos de la Colonia con fray Juan de Córdoba” (Castañón, 2006: 55).

En ese mismo año, ganó por segunda vez las elecciones para diputado y se integró a la XLVI Legislatura (1964-1967). Aunque toda su carrera política fue miembro del Partido Revolucionario Institucional, él se consideraba como "el último vasconcelista que se rindió. Mi caso se puede legítimamente explicar porque no tenía techo, ni sopa, ni sábanas. Llegué a la política por una situación independiente de mis méritos" (Castañón, 2006: 56).10 Al

9 Cruz Bencomo cita el artículo de Henestrosa publicado en El Nacional del 7 de junio de 1998 en la sección que tenía titulada "Reloj literario". Una reconstrucción de anécdotas de primera mano, aunada a un estudio de la vida periodística de Henestrosa se puede consultar en Cruz Bencomo (2001).

10 Castañón cita a su vez el libro Cristina Pacheco (2001), Al pie de la letra, Compilación y prólogo de Mauricio José Sanders Cortés, FCE, México, p. 130. 
mismo tiempo, conservó su sueño -nunca alcanzado- de llegar a ser el gobernador de Oaxaca y combatir los problemas de miseria, corrupción y desigualdad social de su estado.

Cumplió 25 años de casado y viajó con Alfa por primera vez a España, donde visitó Madrid, Toledo, Córdoba, Sevilla y Granada. En la ciudad de la Alhambra reparó en los versos grabados de Francisco de Icaza en piedra en la entrada de la Torre de la Vela: "Dale limosna, mujer/ que no hay en la vida nada/ como la pena de ser/ ciego en Granada” (Icaza, 1994: 32) y se preguntó si los españoles sabrían que su autor era un poeta mexicano. Allí no padeció algún resentimiento por la Malinche, sino que revaloró el mestizaje como rescate de lo mejor de ambas culturas (Reyes, 2005: 305). No le quedaba más que admitir la confluencia étnica que había heredado, no sólo a través de los siglos, sino de su propia carne. En su infancia se preguntaba con mucha frecuencia por qué había salido blanco de piel, mientras sus hermanos eran cobrizos o bronceados. En una carta a su hija Cibeles, se contestó que la sangre blanca también era suya y no debía extrañarle (Henestrosa, 1982: 10).

En las cartas que escribió a su amigo sonorense Herminio Ahumada (el fundador de la Universidad de Sonora, político y atleta olímpico, yerno de José Vasconcelos y traductor al español de las obras de su amigo Langston Hughes), insistía en que se debía romper el esquema clásico de que el vencido asimila sin más y copia al vencedor o que presume de algo como propio, cuando en realidad tiene otras raíces -como el idioma, donde hay vocablos que se conservan en América y que en España están en desuso y al revés-. Por supuesto que distingue el tono seguro y directo del peninsular frente al tono tímido del mexicano, pero eso expresa que el ánimo es diferente en ambos sitios y de ninguna manera puede significar alguna "inferioridad cultural" o "trauma histórico" porque esos conceptos no llevan verdad. Su proyecto para una auténtica integración era que desde niños quedara claro que: 
sin América no se entiende España, a contar del siglo XVI. Muchas de las cosas que a primera vista nos parecen autóctonas de América, tienen en España su remoto origen; otras que se creen españolas pasaron de los pueblos americanos y aquí se aclimataron [en España] [...] Lo menos que puede ocurrir es que el pueblo vencido, cuando en su libertad logró una cultura, tome lo ajeno y lo haga a su manera, lo tiña con su sangre; haga, en una palabra, otra cultura que participe de las dos. No otra cosa hicieron México y todos los otros países en donde los españoles encontraron una cultura original bastante desarrollada [... . Cuando convengamos que no hay americano cabal si no es íntegramente espańol. Cuando aceptemos que no hay españoles íntegros si no tienen una raíz en América. Entonces ocurrirá [...] Tantas cosas hay que ver, que admirar, que apenas me doy cuenta del paso de las horas, de los días, tanto tiempo aplazados de esta visita a España, que todos los hispanoamericanos debieran hacer a tiempo, es decir, en su juventud, cuando les sería útil para su formación intelectual y emotiva. Todos los hispanoamericanos, he dicho, esto es, los que escriben, los que conversan. Porque todavía está haciendo falta entre nosotros la conciencia de que no estaremos cabalmente integrados hasta que no pacifiquemos a los indios y españoles en nuestro corazón (Henestrosa, 1967b: s.n.).

Henestrosa se identificaba profundamente con la figura de Benito Juárez. Ambos eran oaxaqueños, hablaban zapoteco y aprendieron el español después de los 10 años de vida, nacieron en un año 6: 1806 y 1906, pasaron momentos de gran pobreza material y se preocuparon por las injusticias en México. Precisamente, leyendo los apuntes del Benemérito de las Américas, reflexionó que la lengua, en tanto nacional, es un elemento unificador y comunicante al mismo tiempo; puesto que en ella van insertas las preocupaciones y anhelos de su pueblo. Mientras esa lengua esté en construcción, significa que la nación también lo está. Aunque es 
imprescindible preservar la pluralidad lingüística, para que México se integrase debía encontrar una lengua común que fungiera como madre para defender a las lenguas indígenas. Estaba convencido de que el problema mayor y real del indio era la falta de oportunidades económicas, de trabajo y de salario suficiente. Si esos elementos se resolvieran, entonces la lengua española sería hablada sin dificultad y se lograría un bilingüismo natural con una mayor presencia a lo largo de todo el territorio nacional (Reyes, 2005: 333). Desde otro punto de vista, también valoraba la conciencia que la condición de pobreza generó en el líder de la Restauración de la República, como un punto de aprendizaje que veía proyectado en su propia vida:

Sólo la pobreza permite entender sin odio, pero sin blanduras, las proporciones de la injusticia; y sólo en una naturaleza recia y alerta se van edificando en el infortunio ideas concretas y viables para remediarlas. Y así, antes de aprender las letras, supo de memoria la descarnada verdad de su país (Henestrosa, 2001a: 60)

Esta idea del mexicano la podía extender a la perfección hacia el hispanoamericano, el cual se había formado uno solo de la conjunción de dos hombres y, paradójicamente, tenía el "prodigio" de convertirse en dos: por cada cultura representada. Así lo decía el 23 de abril de 1993, en su discurso en la sede de la UNESCO de París, proyectándose en los ejemplos clásicos de nombres como Jerónimo de Aguilar, Doña Marina (Malintzin) y Fernando de Alva Ixtlilxóchitl, hasta enorgullecerse de hablar la misma lengua que Cervantes y de lo único que la conquista no logró tocar:

Yo vengo de lenguas indias. Uno era por cada una de las lenguas que hablaba. Un hombre más fui cuando supe el castellano... En él, Nebrija, aprendí la lengua castellana, mi segunda lengua; logré 
la otra mitad de mi alma: me integré el mestizo que soy (Reyes, 2005: 391).

Por obligación moral, después de no haber ayudado a un niño a comprar un libro de texto - descuido del que siempre se sintió culpable-, en 1984 fundó la Biblioteca Martina Henestrosa en San Francisco Ixhuatán, justo en la casa donde vivió. Esto lo hizo después de haber sido electo Senador, para el periodo de 1982 a 1988. Su trabajo continuó en la administración de Salinas de Gortari como presidente de la Comisión de Asuntos Indígenas y miembro de las de Ciencia y Tecnología, de Corrección y Estilo, Asuntos Editoriales y la nueva de Cultura, que presidía el poeta chiapaneco Jaime Sabines. En ese periodo el Congreso de la Unión reconoció el carácter pluriétnico del Estado mexicano. Sin embargo, esta resolución convencía a Henestrosa, quien insistía en su idea particular de unanimidad común para la nación mexicana. Como otra deuda hacia su natal Oaxaca, donó, cuando tenía 97 años, a su biblioteca más de 40000 ejemplares de su colección privada (Reyes, 2005: 423); libros que había adquirido uno por uno en sus múltiples andanzas por las librerías de viejo en la ciudad de México.

No se puede reducir la interpretación del mestizaje que hizo Henestrosa a una perspectiva desde el poder que "anula la diversidad" y que sacrifica la pluralidad por un orden violento y una unidad forzada con base en la creación de un lenguaje historiográfico que sublima a la patria mexicana por encima de cualquier identidad personal o local, tal como lo hace Zúniga González (1998: 149-150). Si se dice que el oaxaqueño es heredero y continuador del proyecto político del liberalismo mexicano del siglo XIX, esto implica entre otras cosas su defensa de la soberanía nacional y de los derechos civiles frente a cualquier autoritarismo -incluyendo el legalista-. La construcción de la identidad que se propone no es un proyecto impositivo de una sujeción a una determinada serie de leyes que rijan "lo mexicano", sino que apunta hacia una recon- 
ciliación con el pasado en una lectura diametralmente opuesta a la historia oficial y al sistema político imperante. A tal punto que varias personas reconozcan a Henestrosa como un maestro que les enseñó mediante su literatura a respetar la diversidad cultural, a valorar las lenguas indígenas e incluso a amar la lengua española (González Casanova, 2007: 100).

Sin embargo, la labor de Henestrosa no se limitó a la cuestión indígena, mestiza, hispanoamericana o espańola; sino que fue un constante colaborador y amigo de la comunidad judía de México. Escribió muchos artículos para la revista Tribuna Judia, editada en la capital del país; los cuales llegaron a formar un pequeńo libro (1976) y su autor fue homenajeado en múltiples ocasiones. Esta actitud a lo largo de su vida, desde el elemento más local que era para él su Ixhuatán, lo perfila efectivamente como un humanista en la tradición liberal, democrática y republicana que empata con la heredada por los exiliados españoles que aprendieron también las lecciones de los filósofos y pensadores clásicos sobre la condición humana. Andrés se expresó con términos bastante semejantes a dichas preocupaciones en un foro sobre el Seminario de Estudio sobre la Situación de los Judíos en la Unión Soviética en 1972 (año en el que fue nombrado presidente de la Asociación de Escritores de México):

Cuando muere un hombre todos mueren -decía inflamado en sus discursos, el rostro enrojecido, los ojos llanos-. Si se encarcela a uno todos padecen prisión. Si se me niega a hablar mi idioma, a ti y a él niegan a hablar la lengua propia. Persiguen a mi Dios cuando persiguen a tu Dios. Queman mi libro cuando se quema el tuyo. Muero con el que muere por decir la verdad. El que condena al fuego un libro, acaba por quemar al que lo escribió... Por indio, por judío, por negro estoy con todos aquellos que pelean por ser libres, por ser ellos mismos. Indios, negros, judíos son los 
mismos ante mis ojos y mi conciencia. Por eso estoy aquí, con ustedes (Reyes, 2005: 340).

\section{En rescate de algunos liberales olvidados}

Aunque este último apartado está dedicado a los españoles republicanos exiliados después de la Guerra Civil, por razones cronológicas, es necesario comenzar con el estudio que Henestrosa realizó sobre la presencia de José Zorrilla en México. La advertencia es necesaria porque normalmente no sería considerado un escritor de la tradición liberal, pues, aunque su amigo el poeta Miguel de los Santos Álvarez lo invitó a volver a España y prefirió quedarse, se volvió muy cercano a Maximiliano de Habsburgo y a Carlota de Bélgica, quienes le encargaron la creación de un teatro nacional. Sin embargo, Andrés quien era consciente de esto y de sus férreas críticas a la sociedad mexicana, le perdonó su aversión en pro de los recuerdos que se permitió escribir después de estar 11 años en el México decimonónico y de las lecciones que dejó a los poetas locales en ese tiempo (Zorrilla, 1955: VII-XXII).Al parecer, Henestrosa hablaría sobre estos detalles en una conferencia que dio en México titulada precisamente "Zorrilla en México" durante la conmemoración del centenario del triunfo juarista de 1867 (Reyes, 2005: 311).

Como otro aspecto digno de resaltar, sirva como ejemplo la labor ensayística de Andrés en el ámbito del periodismo: género en el cual mantenía viva la memoria de los autores espańoles que forman parte de su obra La otra Nueva España. A inicios de la década de los 40, su amigo cubano José Antonio Fernández de Castro le propuso participar en un proyecto para escribir sobre los periódicos y periodistas en Hispanoamérica. Andrés aceptó y José Antonio le propuso a Daniel Cosío Villegas, director del Fondo de Cultura 
Económica, hacer un apéndice al libro reciente de Georges Weill titulado: El Diario. Vida y función de la prensa periodística, donde no había incluido datos sobre dicha actividad en Hispanoamérica. Don Daniel aceptó y los amigos se repartieron el trabajo. Al final, fue Andrés quien terminaría redactando todo el texto (Reyes, 2005: 173), el cual comenzaba afirmando que aun cuando el periodismo en Hispanoamérica en muchas ocasiones en la historia se mostró más avanzado que en Espańa, había que reconocer que en sus inicios fue una derivación o una prolongación del realizado en la península (Fernández de Castro \& Henestrosa, 1941: 297).

Después de reconocer la resistencia espańola en el siglo XIX frente a la invasión napoleónica, a pesar de las circunstancias adversas, rememoró la Constitución de Cádiz firmada por las Cortes de 1812 donde participaron varios representantes americanos. Se detuvo, como era de esperar, en la cuestión de la libertad de imprenta. Allí explicó que era un capítulo esencial, no porque en América no se practicara como un derecho inalienable, sino porque citando a Martí, se aplicó desde inicios de la Conquista la frase "los derechos se toman y no se piden".11 En su recorrido por la prensa liberal, menciona el periódico El Español de José María Blanco White, calificándolo de "notable", y el Semanario Patriótico de Manuel José Quintana. Al mismo tiempo, recordó el periódico fundado por el ecuatoriano Vicente Rocafuerte llamado Ocios de los Españoles emigrados en Londres, un conjunto de siete volúmenes que se publicaron entre abril de 1824 y octubre de 1826 en la imprenta londinense del emigrado español Marcelino Calero. Allí llegaron a colaborar, entre otros intelectuales de ambos continen-

11 Tales fueron las palabras de José Martí en un Brindis en el banquete celebrado en honor de Adolfo Márquez Sterling en los altos de El Louvre, el 21 de abril de 1879 en La Habana: "Y los derechos se toman, no se piden; se arrancan, no se mendigan". 
tes, liberales como Canga Argüelles, Villanueva y Mendibil (Fernández de Castro \& Henestrosa, 1941: 324, 327, 355).

Henestrosa escribió mucho de los autores españoles más conocidos en el mundo literario e intelectual, como Ortega y Gasset, Azorín, Pío Baroja, León Felipe, Federico García Lorca, Juan Ramón Jiménez, Antonio Machado, Ramón Menéndez Pidal, Marcelino Menéndez y Pelayo, Ramón Valle Inclán, su amigo José Bergamín, Dámaso Alonso y Unamuno. Tuvo la oportunidad de reseñar las obras de varios de ellos o hacer las necrologías, aportando algunos datos interesantes y poco recordados por la extensa bibliografía que se ha escrito sobre ellos. Henestrosa no sólo fomentaba la lectura de autores locales, pues consideraba que también "la literatura de un pueblo la construye todo lo que en él se publica” (Olmedo Muñoz, 2013: 121).12 De Ortega y Gasset, reconoció la influencia que el fundador de la Revista de Occidente tuvo en su estilo literario -y en el de varios escritores hispanoamericanospor su agilidad, destreza y manejo del lenguaje. Andrés recordaba haber leído un texto poco comentado de Ortega llamado "Nuestra Señora del Harnero", cuya lectura compartía con Manuel Moreno Sánchez en el bachillerato (Reyes, 2005: 234).13

Cuando le dieron el Premio Nobel de Literatura a Juan Ramón Jiménez, él anotó que probablemente las primeras letras que

12 Olmedo cita el texto de Henestrosa, "Advertencia" en el Anuario de cuento mexicano.

13 Lo recuerda en la necrología que escribió el jueves 20 de octubre de 1955, donde concluía que "Un viaje por nuestra producción literaria de hace treinta años, podría mostrar cuánto deben los escritores mexicanos que entonces iniciaron su carrera, al gran escritor José Ortega y Gasset que acaba de fallecer". "Ha muerto Ortega y Gasset" (Henestrosa, 2001b: 21). No obstante, un año después reconocía que a pesar de que Ortega era el autor más conocido en México los últimos 25 años atrás, para 1956 "ha perdido, por razones que están en la conciencia de todos, aquel sitio de privilegio que llegó a ocupar entre nosotros (28). 
llegaron del escritor andaluz fueron las de la canción Amapola del Camino y luego algunos textos publicados en la Revista Azul o en la Revista Moderna (Henestrosa, 2001b: 32). De Pío Baroja resaltaba la importancia del estilo literario, el cual recomendaba como ayuda para que los jóvenes literatos mexicanos pudieran cambiar "la errónea creencia de que lo fundamental es escribir bellamente", ya que lo primordial es entrar en contacto directo con la realidad y saber que el arte no está apartado de ella (Henestrosa, 2001b: 37). En conexión con esta idea, recordaba los comentarios alusivos a México, presentes en el libro de Memorias del nacido en San Sebastián. Frente a ello, Henestrosa defendió la búsqueda y las observaciones del escritor español frente a las críticas vertidas en el ámbito mexicano, al cual recordaba la importancia de reconocer toda la verdad con sus miserias y vicios hasta como un ejercicio saludable:

Solamente los pueblos ñoños no pueden resistir que se burlen de ellos. Es una manifestación de debilidad y tontería. Los alemanes habían leído a Schopenhauer y a Nietzsche y no se han escandalizado; los ingleses a Byron, Dickens, Wilde, y ahora a Bernard Shaw; los franceses a Flaubert y a Zola; los norteamericanos a Mark Twain y ahora a Sinclair Lewis. ¿Qué han perdido con eso? Nada. Según Baroja, lo que salva a un país de su ruina es discutir y sentir curiosidad [...] Nunca ha perjudicado a un pueblo que se le digan las verdades, ya por propios, ya por extrańos. Con frecuencia más le perjudican las mentiras y las cantilenas interesadas que, halagando el orgullo nacional, no dejan ver nuestra realidad en su verdadero tamańo y anulan de ese modo la posibilidad de buscarle remedio a sus males. Lo único que reduce el valor de esas denuncias es el ánimo adverso, el prurito de contrastar unos pueblos con otros, para que se vea que sólo la tierra propia es digna de alabanza. Nada de esto hizo Pío Baroja, que con una misma pluma satirizó a otros pueblos y mostró las lacras de su tierra, guiado por esta certeza nietzscheana: lo que no me mata, me hace fuerte. ¿Por qué hemos de ocultar nuestras miserias? ¿Por qué volvernos 
contra los que, sin ánimo de ofensa, muestran aquello que somos nosotros los primeros en condenar y en señalar como cosas que afean nuestra patria? ¿Por qué hemos de discutir si un viajero agradece nuestra hospitalidad o no, sólo porque quiso señalar alguna de estas fealdades que quisiera desterradas de la vida del hombre? (Henestrosa, 2001b: 39-45).

De Ramón Valle Inclán anotó que estuvo en México en dos ocasiones. La primera en el vientre de su madre y en la segunda cuando realizó un viaje con el fin de ser soldado y combatir a los indios sublevados del norte. Su obsesión con llamarse el "general de Tierra Caliente" se halla en su novela Tirano Banderas (Novela de Tierra Caliente). Henestrosa lo presentó como un amante de la cultura indígena viva, un aliado y defensor en la práctica; pues la niña Chole era real, el viaje y el naufragio también. Además, valoró mucho que escribiera México como debe ser, con " $\mathrm{x}$ "; definiéndolo como "un gran amigo de México" (Henestrosa, 2001b: 49-50).

En el mismo sentido, recordó que Dámaso Alonso pasó una estancia en México, particularmente en la capital, para llevar a cabo una investigación histórica sobre el virreinato de la Nueva Espańa a través de un corregidor de la ciudad de México del siglo XVII llamado Alonso Tello de Guzmán, el cual realizó muchas obras públicas según lo que investigó en las Actas de Cabildo del Ayuntamiento de México. Por esto, el autor de Hijos de la ira, esperaba que no se olvidara nombrarlo cuando se rememoraba la historia de la ciudad. Al mismo tiempo, destacó su valoración de las letras novohispanas en un libro editado en Madrid por la Editorial Gredos en 1960 llamado Dos españoles del Siglo de Oro. Un poeta madrileño, latinista y francesista del siglo XVI. El Fabio de la "Epistola Moral": su cara y cruz en Méjico y en España. Allí no sólo mencionó a Ruiz de Alarcón, sino a Eugenio de Salazar y Cebrián Díez Cruzate (Henestrosa, 2001b: 79-81). 
Por el otro lado, Andrés tuvo la oportunidad de conocer o leer a autores espańoles exiliados cuyas obras no han sido del todo recuperadas en la historiografía del liberalismo español. El primer exiliado que vio se llamaba Alejandro García Solalinde. Lo conoció en la Universidad de Stanford cuando se fue becado por la fundación Guggenheim a los Estados Unidos. El profesor Solalinde fue a la estación de ferrocarril por él y lo hospedó en su casa el 20 de julio de 1936. Su esposa y él estaban muy tristes por lo que acontecía en Espańa e iban siguiendo en un mapa colgado en la pared la actividad del ejército republicano (Reyes, 2005: 137). Se trataba del primer exiliado que había visto llorar por el destino de España. Mientras se dirigía a Palo Alto, donde lo esperaba el profesor, se preguntaba si sus autores hispanoamericanos favoritos, de la talla de Sarmiento, Alberti, Martí, Rodó, Bilbao, Varona y González Prada apoyarían a la República; lo que se contestó afirmativamente sin dudarlo (Henestrosa, 2001b: 13-15). Unos años más tarde, reseñó un libro editado por la Colección Málaga de México titulado Éxodo de los republicanos españoles, sin saber a ciencia cierta si fue escrito por Cristina Martín o Gabriel Paz o Paz Márquez o Paz Martín Berlanga, una maestra de escuela que contó su historia desde su exilio hasta su vida en México y sus viajes a Yucatán (Henestrosa, 2001b: 71-74).

Después de Berkeley, siguió su camino hacia la ciudad de Chicago. Allí conoció al profesor de origen español Manuel J. Andrade. Él tenía un proyecto para rastrear las raíces lexicográficas de la lengua zapoteca en la Universidad de Illinois, donde enseñaba lingüística, signos y vocabulario maya. Andrés se unió a ese proyecto y asistió a las clases en búsqueda de la fonética perfecta de su primera lengua. Con los métodos que el profesor le enseńaba para descifrar las estelas mayas, él dilucidaba cómo traducir la palabra "día" entre las opciones Dchí, Dxí, Hxí y Xhí. En esas visitas tanto a la universidad como a su casa, se incorporó a la idea de buscar las 
raíces mayas o mayenses del huave, que se creía de origen quechua (Reyes, 2005: 139).

Otro autor cuyas obras literarias, e incluso científicas, han sido escasamente conocidas dentro del ámbito académico es el médico Antonio Ros. Andrés escribió el proemio del diario de viaje en barco que hizo de Marsella a Shikarpur en la India, donde se enamoró de la princesa de Kalsia, Ragendra Kaur (Reyes, 2001b: 284-285). Ese libro se volvió uno de sus más logrados: Horas de angustia y esperanza. Cuando España perdió la guerra, él se fue a Argelia y luego a París, donde Ros se dio cuenta que su patria estaba perdida. Llegó a residir en México con su hermana la cantante María Ros, dejando a toda su familia en España. Finalmente se unieron de nuevo en México (Henestrosa, 2001b: 59-61, 119-129).

Aunque ya se han citado las cartas que editó Alejandro Finisterre, vale la pena detenerse en el inicio de su amistad. Andrés Henestrosa lo conoció en casa de Griselda Álvarez en una cena. Alejandro era un escritor y periodista exiliado que había fundado la editorial Ecuador 00'0” y llegó a ser su compañero de artículos en El Nacional. Finisterre organizó y preparó él mismo una comida española por el cumpleaños número 57 de Andrés, acompañada de vinos de la Rioja. El libro Desde México y España surgió después de que Alejandro leyera las cartas de Andrés escritas para Herminio Ahumada, que publicó en su editorial (Reyes, 2005: 287-288, 304-305).

Miguel de Unamuno, como ya se ha ido descubriendo en las investigaciones más recientes (Gordo, 2013), estuvo en México durante su infancia. En particular, lo que pudo recordar de esa estancia lo plasmó en su libro Recuerdos de niñez y de mocedad. Don Miguel estuvo en Nayarit, de donde se llevó una gran biblioteca a España. Al mismo tiempo, quedaría marcado por una escena representada en cera del fusilamiento de Maximiliano en Querétaro. Parece ser que esta impresión la conservó tal cual cuando tradujo 
el poema Miramare de Carducci. Además de esto, Andrés escribió sobre un homenaje que le hicieron a Unamuno y a García Lorca los miembros de la Escuela Nacional de Ciencias Políticas y Sociales de la UNAM (Henestrosa, 2001b: 27-30). No fue la única vez que Henestrosa recordó al filósofo vasco. En otro artículo, llegó a llamarlo "juarista", aludiendo a sus andanzas juveniles por Acaponeta. En sus Recuerdos de niñez y de mocedad, Unamuno reconocía a Juárez como el verdadero padre de la patria mexicana (Reyes, 2005: 51-53).

La semana siguiente a la que escribió su artículo "Unamuno, juarista", se vio en la necesidad de ampliar la información al respecto debido a las peticiones de varias personas que se sorprendieron al saber que Unamuno estuvo en México. De esta forma, Andrés confesó la fuente donde se enteró de las andanzas de Unamuno por Tepic. Leyó un ensayo de Manuel Torre Iglesias, quien era profesor en Nayarit y que había sido alumno directo de Unamuno en España. El profesor se reunió con su amigo Javier Belauzarán en una tarde de agosto de 1966 en la plaza de Tepic y le dio una foto de Unamuno cuando era adolescente; tomada precisamente en dicha ciudad. Belauzarán partió a Costa Rica y Torre Iglesias fue profesor de literatura en la Escuela Normal Superior de Nayarit. Su amigo sabía que preparaba un libro sobre Unamuno y por eso le regaló la fotografía que tenía. Andrés justificó su nota anterior, demostrando que no la había inventado y se declaró expectante de la publicación del libro de Torre Iglesias (Henestrosa, 2001b: 55-57).

La amistad del escritor oaxaqueńo con los miembros de la otra Nueva Espańa le permitía observar la necesidad de una reconciliación entre México y España, actividad que veía plasmada en sus amigos espańoles Arturo Perucho y Miguel Prieto con el mexicano José Mancisidor; quienes se reunían "para defender la cultura y la herencia de libertad de nuestros dos pueblos". De alguna forma, esto lo consideraba una proyección de un discurso que pronunció 
Benito Juárez en Oaxaca donde "proclamó la concordia entre los espańoles y los mexicanos para la defensa de aquellas mismas causas, justas y sagradas" (Henestrosa, 2001b: 23-25).

En la misma línea de amistad, conoció a Luis Suárez, quien llegó a México y buscó con mucha dificultad el poder ganarse la vida. Cuando se logró instalar en una posición más cómoda y lo conoció, asistieron a unas bodas en Juchitán, evento del cual escribió un libro que Henestrosa prologaría. Veía a Luis con la mirada puesta tanto en México como en España, recorriendo todo el país y redactando varias crónicas de las impresiones que le dejaron sus viajes (Henestrosa, 2001b: 95-97). Un caso ligeramente distinto fue el del madrileño Antonio Robles o Antoniorrobles, quien vivió 38 ańos en México y se dedicó profundamente a la escritura de cuentos, novelas y artículos. También formó parte de la colonia Nueva España, pues vivía en la calle de Ejido -prolongación de la avenida Juárez en la Tabacalera-. Andrés se llevó muy bien con él y su esposa Angelines. Después de 38 ańos, volvieron a España, a una casa en El Escorial y murió en Madrid. Se lamentó mucho no haberlo visitado en el viaje que hizo a la península. Revisando su obra, se dio cuenta que a México le falta hacer un balance de la deuda que tiene con los exiliados republicanos (Henestrosa, 2001b: 99-101).

En suma, no se trataba de una especie de adopción o nacionalización cultural de los republicanos españoles, ni mucho menos es defendible la idea de una relación totalmente jerárquica de magisterio desde España hacia México, como una mala interpretación de la frase "maestros del exilio" puede sugerir. El reto que se puede plantear consistía y consiste actualmente en partir de la riqueza cultural, admitiendo la diversidad y la singularidad de una sociedad, para llegar así a una convivencia en igualdad de condiciones entre personas a las que no las determina una nacionalidad o una 
ideología; sino que éstas mismas son herramientas que abren y conforman diálogos de respeto y conocimiento mutuo.

\section{Bibliografía}

Castañón, Adolfo, 2006, "Cien años de Andrés Henestrosa. El hombre que dispersó su sombra", Revista de la Universidad de México, núm. 33, pp. 48-58.

Cruz Bencomo, Adán, 2001, Henestrosa, nombre y renombre, México, Diana.

,2003, Valoración y rescate de la obra periodística de Andrés Henestrosa, Tesis inédita de licenciatura en Lengua y Literaturas Hispánicas, México, UNAM.

Fernández de Castro, José Antonio \& Henestrosa, Andrés, 1941, "Apéndice. Periodismo y periodistas de Hispanoamérica", en Weill, Georges, El diario. Historia y función de la prensa histórica, versión española de Paulino Masip, México, FCE, pp. 376-412.

González Casanova, Dolores, 2007, "Meanderings and Memories of Andrés Henestrosa”, Voices of Mexico, núm. 81, septiembrediciembre, pp. 100-102.

González Freire, José Manuel, 2015, "Los cuatro abuelos: epístola a Griselda Álvarez de Henestrosa", Revista Inclusiones, Revista de Humanidades y ciencias sociales, vol. II, núm. 2, abril-junio, pp. 187-194.

Gordo Piñar, Gemma, 2013, Miguel de Unamuno y México. Relación y recepción, Tesis inédita de Doctorado en Pensamiento Español e Iberoamericano, Universidad Autónoma de Madrid, $514 \mathrm{pp}$.

Henestrosa, Andrés, 1967a, Retrato de mi madre, México, Bibliófilos oaxaqueños. 
, 1967 b, Desde México y España, México, Alejandro Finisterre Editor.

, 1976, De Ixhuatán, mi tierra, a Jerusalén, tierra del Señor, México, Editorial Tribuna.

, 1982, Entonces vivía yo en Ixhuatán y me llamaba Andrés Morales, México, Bibliófilos oaxaqueños.

, 2001a, "Nacer para estatua”, Letras Libres, núm. 29, año 3, México, Mayo, pp. 60-69. , 2001b, La otra Nueva España, México, Porrúa/UCLM. , 2009, Los hombres que dispersó la danza, México, Porrúa.

Icaza, Francisco de, 1994, Páginas escogidas, México, UNAM.

Martínez, José Luis (comp.), 1942, Literatura indígena moderna. A. MedizBolio. E. Abreu Gómez. A. Henestrosa, México, Ediciones Mensaje.

Olmedo Muñoz, Iliana, 2013, "El lugar de la narrativa del exilio republicano en la historiografía literaria mexicana", Secuencia. Revista de historia y ciencias sociales, núm. 85, enero-abril, pp. 111-137.

Paz, Octavio, 2001, “Agua de la memoria: Andrés Henestrosa”, en Generaciones y semblanzas. Dominio Mexicano. Obras Completas, México, Galaxia Gutenberg/Círculo de Lectores, pp. 353-354.

Riva Palacio, Vicente, 2006, El parnaso mexicano. Segunda Serie I, México, CONACULTA/UNAM.

Reyes Haiducovich, Alexandra, 2005, Henestrosa, hombre de un siglo, México, SNTE/Porrúa/Senado de la República.

Roa García, Raúl, 1938, José Martí y el destino americano, La Habana, Bouza.

Zorrilla, José, 1955, México y los mexicanos, México, Ediciones de Andrea. 
Zúñiga González, Víctor A., 1998, "De cómo hablamos de los indígenas los mexicanos (no indígenas) en el México actual”, Región y Sociedad, vol. IX, núm. 15, enero-junio, pp. 131-164.

Recibido: 14 de junio de 2016 Aceptado: 18 de noviembre de 2016 